\title{
Inguinal hernia containing ovary presenting as groin mass in infant
}

\author{
S Ansari, P L Sah, K Dhungel, K Ahmad, M K Gupta, R K Rauniyar, A Panwar \\ Department of Radiodiagnosis \\ B.P. Koirala Institute of Health Sciences, Dharan, Nepal
}

\begin{abstract}
Inguinal hernias are one of the differential diagnoses of inguinal masses in infants in both males and females. In females, an irreducible ovarian inguinal hernia tends to undergo torsion and sometimes infarction. Sonography should be used as the imaging modality of choice for the evaluation and characterization. We present a case of 19 days old female infant presented with right groin mass, diagnosed as right inguinal hernia containing right ovary on ultrasonography.
\end{abstract}

Keywords: Groin mass; Inguinal hernia; Ovarian herniation; Ultrasonography.

\section{Introduction}

Hernia is defined as the protrusion of an organ or the fascia of an organ through the wall of the cavity that normally contains it. The most common etiology of inguinal masses in infants is inguinal hernias accounting for $0.8 \%$ to $4.4 \%{ }^{1}$. In infants, inguinal hernias are found about 6 times more common in male than in female ${ }^{2}$. These are right sided in nearly $60 \%$ cases, left sided in $30 \%$ and bilateral in $10 \%$ cases $^{1}$. Ovary is seen in approximately $15 \%$ to $20 \%$ of inguinal hernias in female; however fallopian tube can also be seen occasionally ${ }^{1}$. Clinically they present as an asymptomatic palpable mass over the labia majora $^{3}$.

\section{Case presentation}

A 19 days old female infant was presented to our department for ultrasonography of an irreducible mass in her right groin. Physical examination revealed a $3 \times 3 \mathrm{~cm}$, soft, irreducible right groin mass in the region of inguinal and labium major. No organomegaly was noted and there was no history of fever. She was born at 36 weeks of gestation and weighing 2400 gm. Ultrasonography revealed an oval structure of

Address for correspondence

Dr. Sajid Ansari, MD, Senior Resident

Department of Radiodiagnosis, B.P. Koirala Institute of Health

Sciences, Dharan, Nepal

Email: drsajidansari@yahoo.co.in size $2.5 \times 2.5 \mathrm{~cm}$ with multiple cystic areas within (consistent with right ovary) seen herniated through a defect measuring $7 \mathrm{~mm}$ in the right inguinal canal (Figure 1). No vascular flow seen on Doppler sonography (Figure 2). Left ovary was normal in position and size (Figure 3). Sonographic examination of the abdomen showed no abnormalities. Our findings were confirmed by surgery.

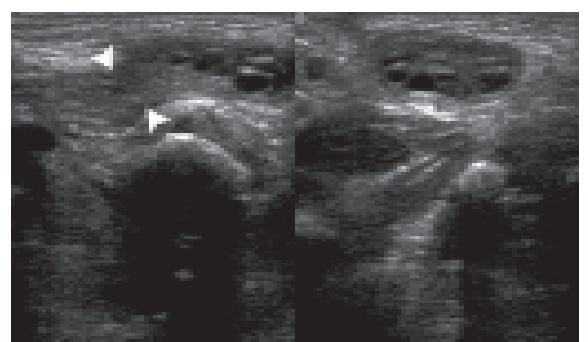

Fig 1: Sonographic image showing a defect (between white arrowheads) in the right inguinal canal through which right ovary is herniated.

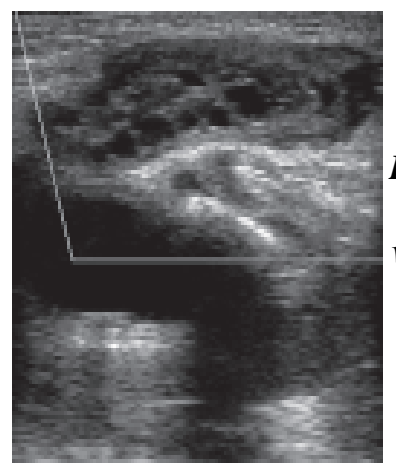

Fig 2: Doppler sonographic image showing no vascularity in the herniated right ovary. 


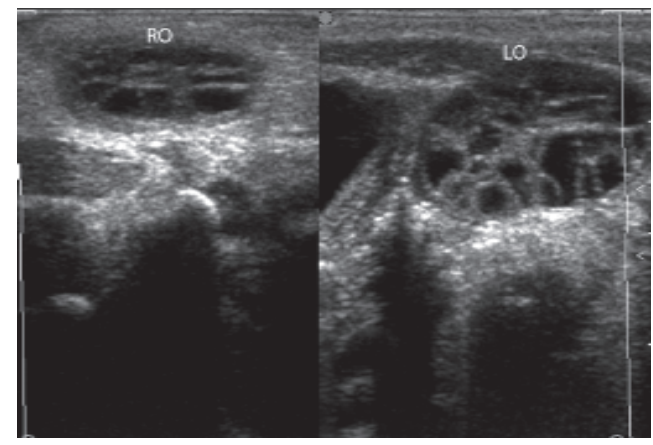

Fig 3: Sonographic image showing herniated right ovary $(R O)$ and normally placed left ovary $(L O)$.

\section{Discussion}

During gestational period, the gonads are formed along the ventromedial aspect of the urogenital ridge at about $6^{\text {th }}$ week and reaches the internal inguinal ring by the $12^{\text {th }}$ week ${ }^{4}$. The embryologic basis of inguinal hernias is similar in male and female fetuses. Depending on the gender, at around $6^{\text {th }}$ month of gestation, the processus vaginalis arises as an evagination of parietal peritoneum and is accompanied by testis or round ligament of the uterus and passes through the inguinal canal toward the scrotum or labium major ${ }^{5,6}$. In females, the processus vaginalis is smaller and disappears by 8 months of gestation; however its patency may persist postnatally ${ }^{7}$. If patency persists, the patent processus is termed the canal of Nuck and its failure to closure causes hydrocele or hernia ${ }^{8}$. Hernia of the canal of Nuck is also a very rare condition.

In inguinal canal hernia, the herniation of small intestine, bladder, omentum, testes, ovary, fallopian tube and uterus have all been described. Inguinal hernia in infant containing uterus and fallopian tube is very rare, and may be associated with mullerian anomalies; so meticulous gynecological follow-up is advised until the childbearing age ${ }^{9}$. In females, non-reducible ovarian inguinal hernias at the time of surgery are found in about 4 to 37\%; torsion occurs in nearly 2 to $33 \%$ of them and sometimes infarction occurs ${ }^{10}$. Therefore even an asymptomatic non-reducible ovarian hernia should be treated with urgent manual or operative reduction to avoid an incarceration ${ }^{4}$. Reduction is successful in 70 to $90 \%$ of cases. Surgical repair can be done once the swelling diminishes ${ }^{11,12}$.

Lymphadenopathy, cystic lymphangioma, epidermal inclusion cyst or malignant tumors (likerhabdomyosarcoma or metastasis) should be considered in the differential diagnosis of a pathologic groin mass in a girl ${ }^{13}$.

\section{Summary}

This case has been reported to increase the awareness that thorough evaluation should be done in a female infant with an inguinal hernia to determine the presence of ovaries because the ovaries are at increased risk of incarceration and subsequent infarction. For evaluation, characterization and differential diagnosis of inguinal masses, sonography should be used as the imaging modality of choice.

\section{References}

1. Ziegler MM. Diagnosis of inguinal hernia and hydrocele. Pediatr Rev 1994; 15:286-288.

2. Kapur P, Caty MG, Glick PL. Pediatric hernias and hydroceles. Pediatr Clin North Am 1998; 45:773-789.

3. Huang CS, Luo CC, Chao HC, Chu SM, Yu YJ, Yen JB. The presentation of asymptomatic palpable movable mass in female inguinal hernia. Eur J Pediatr 2003; 162:493-5.

4. Laing FC, Townsend BA, Rodriguez JR. Ovarycontaining hernia in a premature infant: sonographic diagnosis. J Ultrasound Med 2007; 26:985-987.

5. Ming YC, Luo CC, Chao HC, Chu SM. Inguinal hernia containing uterus and uterine adnexa in female infants: report of two cases. Pediatr Neonatol 2011; 52:103-105.

6. Khanna PC, Ponsky T, Zagol B. Sonographic appearance of canal of Nuck hydrocele. Pediatr Radiol 2007; 37:603-6.

7. Ozbey H, Ratschek M, Schimple G, Hollwarth ME. Ovary in hernia sac: prolapsed or a descended gonad? J Pediatr Surg 1999; 34:977-80.

8. Kucera P, Glazer J. Hydrocele of the canal of Nuck. A report of four cases. J Reprod Med 1985; 30:439-42.

9. Gnidec AA, Marshall DG. Incarcerated direct inguinal hernia containing uterus, both ovaries, and fallopian tubes. J Pediatr Surg 1986; 2:986.

10. Boley SJ, Cahn D, Lauer T, Weinberg G, Kleinhaus S. The irreducible ovary: a true emergency. J Pediatr Surg. 1991; 26:1035-8.

11. Lau ST, Lee YH, Caty MG. Current management of hernias and hydroceles. Semin Pediatr Surg. 2007; 16:50-7.

12. Fleisher GR, Ludwig S, Henretig F. Textbook of pediatric emergency medicine. 5th ed. Philadelphia, PA: Lippincott, Williams and Wilkins; 2005.

13. Park SJ, Lee HK, Hong HS, et al. Hydrocele of the canal of Nuck in a girl: ultrasound and MR appearance. Br J Radiol 2004; 77:243-244. 